\title{
Leptin upregulates smooth muscle cell expression of MMP-9 to promote plaque destabilization by activating AP-1 via the leptin receptor/MAPK/ERK signaling pathways
}

\author{
RUIJIE LIU ${ }^{1 *}$, BENFA CHEN $^{2 *}$, JIEMIN CHEN $^{1 *}$ and JUN LAN ${ }^{1}$ \\ ${ }^{1}$ Department of Cardiology, Dongguan Third People's Hospital; ${ }^{2}$ Department of Cardiology, \\ Donghua Hospital of Sun Yat-sen University, Dongguan, Guangdong 523326, P.R. China
}

Received December 15, 2017; Accepted July 2, 2018

DOI: $10.3892 /$ etm.2018.6853

\begin{abstract}
Leptin has been reported to be expressed in carotid atherosclerotic plaques, where it can promote lesion instability. Matrix metalloproteinases (MMPs) produced by smooth muscle cells (SMCs) are known to contribute to the weakening of atherosclerotic plaques via the degradation of extracellular matrix (ECM) proteins. The present study investigated whether leptin promotes plaque rupture by increasing the expression of MMP in SMCs in vivo and in vitro. In vivo, the neointima/media ratio and expression of MMP in the carotid artery of $o b / o b$ mice were measured following carotid ligation and systemic administration of leptin. In vitro, the effect of leptin treatment on the expression of MMP in isolated SMCs and the underlying signaling pathways were investigated by gelatin zymography and western blot analysis. The results demonstrated that leptin treatment significantly increased the neointima/media ratio and expression of MMP-9 in the carotid artery of mice following carotid ligation. In vitro, leptin also significantly increased the expression and activity of MMP-9 in cultured SMCs in a dose-dependent manner. Leptin also increased the production of MMP-9 by activating leptin receptor and mitogen-activated protein kinases, including extracellular signal-regulated kinase (ERK) and c-Jun N-terminal kinase (JNK), which in turn enhanced the binding of the transcription factor activator protein-1 (AP-1) to the MMP-9 promoter. The inhibition of leptin-activated phosphorylation of ERK and
\end{abstract}

Correspondence to: Dr Jun Lan, Department of Cardiology, Dongguan Third People's Hospital, 1 Xianglong Road, Dongguan, Guangdong 523326, P.R. China

E-mail: lanjun159753@126.com

*Contributed equally

Abbreviations: MMPs, matrix metalloproteinases; SMC, smooth muscle cell; ACS, acute coronary syndrome; AP-1, luciferase reporter gene

Key words: activator protein-1, leptin, matrix metalloproteinase, plaque instability, smooth muscle cells
JNK suppressed the leptin-stimulated expression of AP-1 and MMP-9. Leptin treatment induced the expression of MMP-9 in SMCs, suggesting that leptin may have substantial involvement in plaque rupture by promoting the degradation of ECM.

\section{Introduction}

Atherosclerotic plaque rupture or erosion is the main cause of arterial thrombosis, which leads to a setting of acute ischemic cardiovascular disease, i.e., acute coronary syndrome (ACS) (1). The complex mechanisms involved in lesion progression and instability include the recruitment and activation of monocytes, macrophages and other inflammatory cells, neovascularization from the vasa vasorum, perivascular inflammation, and importantly, the synthesis of proatherogenic cytokines, including tissue factor, which renders the lesion more thrombogenic, and proteolytic enzymes, including matrix metalloproteinase (MMP)-2 and -9 (2). MMPs can promote dispersion of the fibrous lesion via the degradation of extracellular matrix (ECM) proteins, including collagens, proteoglycans, fibronectin and elastin. Multiple enzymes have been shown to be overexpressed in the shoulder regions of atherosclerotic plaques and to contribute to plaque destabilization, particularly by degrading the fibrous cap (3). Vascular smooth muscle cells (VSMCs) are the major cellular component of the vessel wall and are key in vascular function. Plaque stability largely depends on VSMC function, as these cells have a high capacity to secrete MMPs, which regulate the balance between ECM synthesis and degradation (4-8).

Adipose tissue, as an endocrine organ that produces and secretes bioactive adipokines with pro- and anti-inflammatory properties, can contribute to the inflammatory activation in acute coronary syndrome (9). The increased expression and secretion of resistin in epicardial adipose tissue of patients is associated with ACS (10). Leptin is an adipocyte-derived hormone, which was identified in 1994, and its main function is to reflect the body's fat stores and act in maintaining energy homeostasis. The expression of leptin is also an established independent cardiovascular risk factor, which is important in associated diseases, including coronary atherosclerosis (11-14).

In neurologically symptomatic patients, leptin has been reported to be locally synthesized in carotid atherosclerotic 
plaques where it can promote lesion instability by increasing the expression of MMPs (15). In addition, treatment with leptin promotes the progression of abdominal aortic aneurysm in Apo-E mice by increasing the expression of MMP-9 and -12 , thereby stimulating medial degeneration (16). It is known that MMPs in plaques are primarily expressed by macrophages and SMCs, and it has been demonstrated that leptin can promote SMC proliferation and migration (17-20). However, whether leptin can stimulate the expression of MMP in SMCs to accelerate plaque destabilization had not been determined. The present study hypothesized that leptin upregulates the expression of MMP in VSMCs to promote plaque destabilization. To confirm this hypothesis, the effect of leptin on the expression of MMP in VSMCs was examined in vivo and in vitro, and the relevant signaling pathways and molecular mechanisms were identified.

\section{Materials and methods}

Animal experiments. C57BL/6 and ob/ob mice (leptin deficiency, C57BL/6 background) were purchased from Nanjing Biomedical Research Institute of Nanjing University (Nanjing, China). The ob/ob mouse strain is a mutant mouse, which eats excessively due to mutations in the leptin gene (leptin deficiency). The experiments involving animals were performed according to the guidelines and ethical standards of the Animal Care and Use Ethics Committees of Southern Medical University (Guangzhou, China; permit no. SCXK 2006-0116). At 8 weeks of age, the mice were anesthetized by intraperitoneal injection of a ketamine $(100 \mathrm{mg} / \mathrm{kg})$ and xylazine $(10 \mathrm{mg} / \mathrm{kg})$ mixture, and carotid ligation was performed. The mice were then divided into four groups: Sham (C57BL/6, $n=6)$, wild-type (WT) C57BL/6 mice $(n=6)$, $o b / o b$ mice $(\mathrm{n}=6)$, and $o b / o b$ mice treated with leptin $(\mathrm{n}=6)$. Osmotic minipumps (Alzet, Durect Corporation, Cupertino, CA, USA) filled with either recombinant leptin (PeproTech EC, Ltd., London, UK) or phosphate-buffered saline (PBS) were implanted into the abdominal cavity and set to deliver a dose of $1 \mu \mathrm{g} / \mathrm{g} / \mathrm{d}$. The animals were fed a standard chow diet and were housed at $25^{\circ} \mathrm{C}$ with 12-h light/dark cycles and a humidity $\leq 60 \%$. All animals were sacrificed at 4 weeks post-surgery. The carotid artery was carefully excised, fixed in $4 \%$ paraformaldehyde overnight at $4^{\circ} \mathrm{C}$ and embedded in paraffin for $30 \mathrm{~min}$ at $4^{\circ} \mathrm{C}$. Cross-sections $(5 \mathrm{~mm})$ were cut and stained with hematoxylin and eosin at room temperature for $10 \mathrm{~min}$. The intima was defined as tissue between lumen and internal elastic lamina, and media was defined as tissue between internal elastic lamina and external elastic lamina. The intimal and medial areas were measured utilizing image analysis software (ImageJ 1.48; National Institutes of Health, Bethesda, MD, USA) and the neointima/media area ratio was calculated.

Gelatin zymography for arterial tissue. Zymographic analysis was performed in all the animals sacrificed at 4 weeks. The vessels were excised, washed with Hanks' buffer (Applygen Technologies, Inc., Beijing, China) and rapidly frozen in liquid nitrogen, prior to pulverization using a mortar and pestle. The powders were resuspended in ice-cold lysis buffer, containing $3 \mathrm{M} \mathrm{NaCl}, 1 \mathrm{M}$ Tris- $\mathrm{HCl}$ (pH 7.4), 0.5M EDTA, 100 mM PMSF and $10 \%$ Triton $\mathrm{X}-100$ in $\mathrm{ddH}_{2} \mathrm{O}$, at a ratio of $0.3 \mathrm{ml} / 10 \mathrm{mg}$ wet weight. Samples were lysed on ice for $30 \mathrm{~min}$ and centrifuged for $25 \mathrm{~min}\left(12,000 \mathrm{x} \mathrm{g}, 4^{\circ} \mathrm{C}\right)$. Supernatants were retained and protein concentrations were measured using a bicinchoninic acid assay. Protein sample loading was consistently adjusted to protein concentration. The protein samples $(80 \mu \mathrm{g})$ were mixed in a SDS-PAGE $2 X$ loading buffer [4\% SDS, $100 \mathrm{nM}$ Tris-Cl (pH 6.8), 20\% glycerol and $0.02 \%$ bromophenol blue] and applied to an $8 \%$ SDS-PAGE gel containing $1 \mathrm{mg} / \mathrm{ml}$ gelatin. The gels were subjected to low current constant current electrophoresis, rinsed twice for $30 \mathrm{~min}$ with buffer at room temperature and then incubated for $1-5 \mathrm{~h}$ at $37^{\circ} \mathrm{C}$. Following staining with Coomassie brilliant blue, gray-scale analysis of gel images was performed using ImageJ 1.48 software (National Institutes of Health).

Cell culture and treatment with inhibitor and blocking antibody. To determine whether leptin induces the expression of MMP in VSMCs via the mitogen-activated protein kinase (MAPK)/extracellular signal-regulated kinase (ERK)/activator protein-1 (AP-1) pathway, primary VSMCs were isolated by enzymatic digestion of the thoracic aortic media from C57BL/6 male mice (average weight $22 \mathrm{~g}$, 7-8 weeks old). The isolated cells were cultured at $37^{\circ} \mathrm{C}$ in a $5 \% \mathrm{CO}_{2}$ humidified atmosphere. The VSMCs were identified by immunofluorescence staining. Early passage VSMCs at $90 \%$ confluence were exposed to serum starvation for $24 \mathrm{~h}$ in high-glucose Dulbecco's modified Eagle's medium (DMEM HG; Gibco; Thermo Fisher Scientific, Inc., Waltham, MA, USA). Cells $\left(1 \times 10^{6}\right)$ were treated with leptin $(1 \mu \mathrm{g} / \mathrm{ml})$ or leptin $(1 \mu \mathrm{g} / \mathrm{ml})$ plus inhibitors (or blocking antibodies) for $24 \mathrm{~h}$ in $37^{\circ} \mathrm{C}$, including ERK kinase (MEK)1/2 inhibitor (U0126; $10 \mu \mathrm{M}$ ), c-Jun N-terminal kinase (JNK) inhibitor (sp600125; \#8177; $10 \mu \mathrm{M}$ ) all from Cell Signaling Technology, Inc. (Danvers, MA, USA). SMC basal medium served as a control treatment. The effective and safe doses of the inhibitors or blocking antibodies were determined by preliminary experiments. The conditioned medium was collected.

Small interfering RNA (siRNA). The following siRNAs were purchased from Invitrogen; Thermo Fisher Scientific, Inc. (Waltham, MA, USA): Leptin receptor siRNA-1, 5'-ACU CCGAAACUGGUCCAUGAUCUGC-3' and leptin receptor siRNA-2, 5'-AUAUCCUGGUAAACGAUCUCAGUUA-3'. Negative control siRNA (stealth RNA; negative control; cat. no. 12935-200) was also obtained from Invitrogen; Thermo Fisher Scientific, Inc. The VSMCs were cultured in DMEM containing $25 \mathrm{mM}$ glucose and $10 \%$ (v/v) heat-inactivated fetal calf serum (Gibco; Thermo Fisher Scientific, Inc.) at $37^{\circ} \mathrm{C}$ in a $5 \% \mathrm{CO}_{2}$ humidified atmosphere. To knock down the expression of leptin receptor in VSMCs, the VMSCs were transfected with the pcPURm6i35 shRNA expression vector (Invitrogen; Thermo Fisher Scientific, Inc.) containing the target sequence for mouse leptin receptor by reverse transfection using Lipofectamine 2000 reagent (Invitrogen; Thermo Fisher Scientific, Inc.).

Luciferase reporter assay. VSMCs were co-transfected with luciferase reporter gene (AP-1) constructs and $\beta$-galactosidase using Lipofectamine 2000 (Invitrogen; Thermo Fisher 

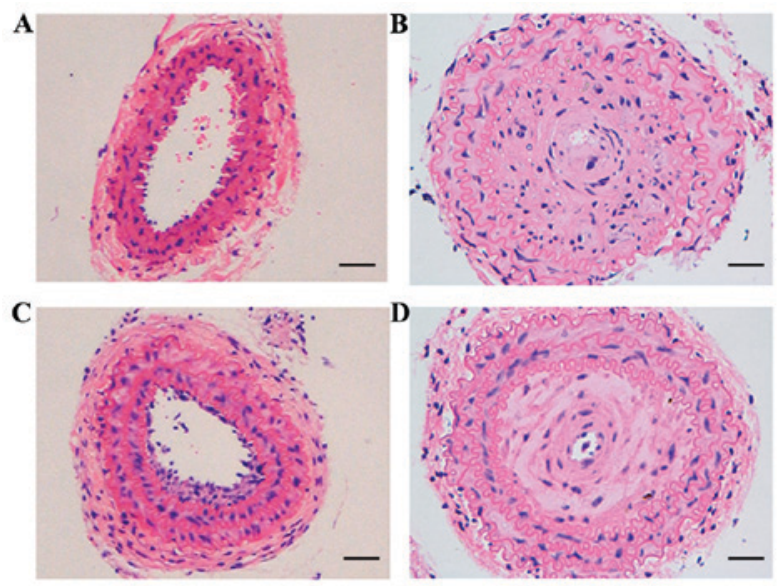

F

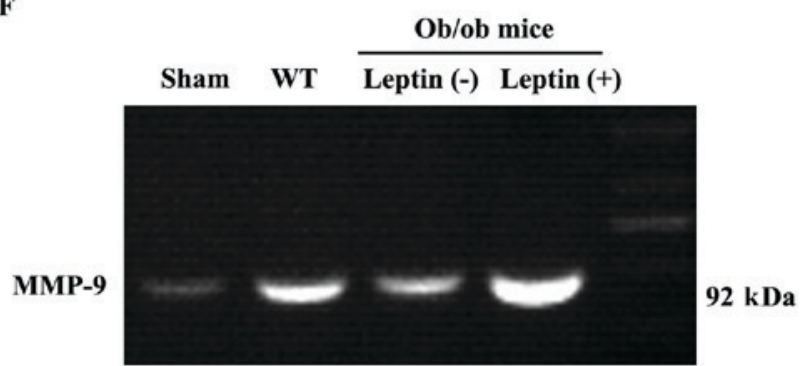

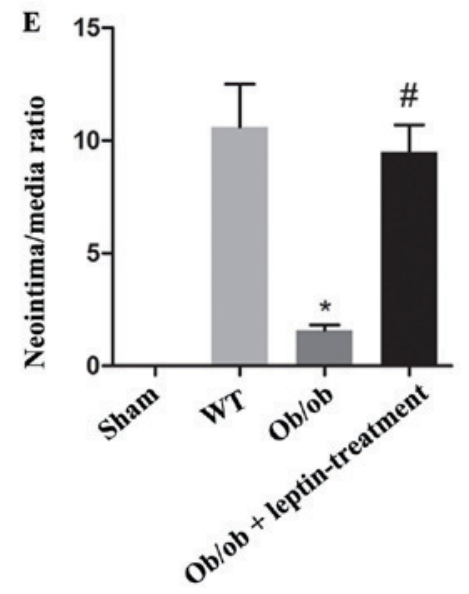

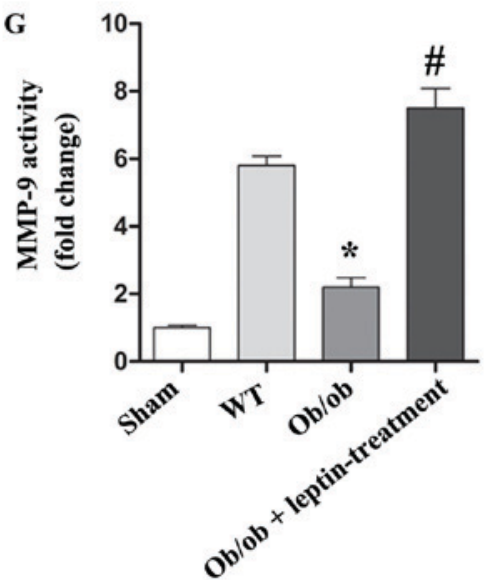

Figure 1. Leptin significantly promotes neointimal hyperplasia and expression of MMP-9 in the carotid artery of ob/ob mice following carotid ligation. Carotid ligation was performed on 8-week-old mice, followed by provision of a standard diet for 4 weeks and sacrifice; injured carotid arteries were excised and processed for hematoxylin and eosin staining (scale bar=50 $\mu \mathrm{m}$ ). (A) Sham group, (B) WT mice group, (C) $o b / o b$ mice group, (D) ob/ob mice + leptin treatment group. (E) Representative histogram of the neointimal/media ratio in each group. (F) Injured carotid arteries were excised and processed for gelatin zymography; leptin significantly induced MMP-9 proteolytic activity in the carotid artery following carotid ligation. (G) Representative histogram of MMP-9 proteolytic activity in each group. ${ }^{*} \mathrm{P}<0.05$ vs. WT mice group; ${ }^{*} \mathrm{P}<0.05$ vs. ob/ob mice group. Data are presented as the mean \pm standard error of the mean. MMP-9, matrix metalloproteinase-9; WT, wild-type.

Scientific, Inc.) for $24 \mathrm{~h}$ according to the manufacturer's protocol and cells were treated with $1 \mu \mathrm{g} / \mathrm{ml}$ leptin for $24 \mathrm{~h}$ at $37^{\circ} \mathrm{C}$, with or without $1 \mathrm{~h}$ of pretreatment with inhibitors. Luciferase activity was determined using a luciferase assay kit (Promega, Madison, WI, USA).

Reverse transcription-quantitative polymerase chain reaction analysis $(R T-q P C R)$. Cell RNA was extracted using TRIzol reagent (Invitrogen; Thermo Fisher Scientific, Inc.). cDNA was synthesized using the PrimeScript RT Reagent kit for $15 \mathrm{~min}$ at $42^{\circ} \mathrm{C}$ (Takara Bio, Inc., Shiga, Japan). cDNA template (50 ng) was amplified using SYBER Premix Ex Taq ${ }^{\mathrm{TM}}$ II (Takara Bio, Inc.) according to the manufacturer's instructions. The primer sequences were as follows: MMP-9, antisense, 5'-GCTGAC TACGATAAGGACGGC-3' and sense, 5'-AGGAAGACG AAGGGGAAGACG-3'; leptin receptor, antisense, 5'-ACC TGGCATATCCAATCTCTCC-3' and sense, 5'-TTCAAA GCCGAGGCATTGTTT-3'; and $\beta$-actin, forward, 5'-ATG GGTCAGAAGGACTCCTACG-3' and reverse, 5'-AGTGGT ACGACCAGAGGCATAC-3'. The mRNA expression of $\beta$-actin was used as a control. qPCR was performed using the following conditions: $95^{\circ} \mathrm{C}$ for $60 \mathrm{sec}$, followed by 35 cycles of $60^{\circ} \mathrm{C}$ for $30 \mathrm{sec}$ and $72^{\circ} \mathrm{C}$ for $100 \mathrm{sec}$. Each sample was replicated at least three times. Relative quantification was determined using the $2^{-\Delta \Delta \mathrm{Cq}}$ method with $\beta$-actin as reference gene (21).

Western blot analysis. Cells were rinsed with ice-cold PBS and proteins were extracted with lysis buffer (Thermo Fisher Scientific, Inc.) for $30 \mathrm{~min}$ on ice. The extracts were centrifuged $\left(13,400 \mathrm{x} \mathrm{g} ; 4^{\circ} \mathrm{C} ; 20 \mathrm{~min}\right)$ and the supernatants were obtained. Protein concentrations were determined using the DC protein assay (Bio-Rad Laboratories, Inc., Hercules, CA, USA) and proteins $(40 \mu \mathrm{g})$ were subjected to electrophoresis on a 10\% SDS-PAGE gel (Bio-Rad Laboratories, Inc.). The proteins were then transferred onto polyvinylidene difluoride membranes (Immobilon-P; EMD Millipore, Billerica, MA, USA). The membranes were blocked in PBS with Tween 20 (PBST, pH 7.4) containing 5\% bovine serum albumin and were probed with antibodies targeting phosphorylated (p-)ERK (AF1018; $0.1 \mu \mathrm{g} / \mathrm{ml}$ ); ERK (MAB15761; $1 \mu \mathrm{g} / \mathrm{ml} ; \mathrm{F} 1018$ ); p-JNK (AF1205; $0.5 \mu \mathrm{g} / \mathrm{ml}$ ); JNK (MAB1387; $0.2 \mu \mathrm{g} / \mathrm{ml}$ ); leptin receptor (AF497; $0.1 \mu \mathrm{g} / \mathrm{ml}$ ); MMP-2 (AF1488; $0.1 \mu \mathrm{g} / \mathrm{ml}$ ); and MMP-9 (AF909; $0.25 \mu \mathrm{g} / \mathrm{ml}$; all 
$\mathbf{A}$

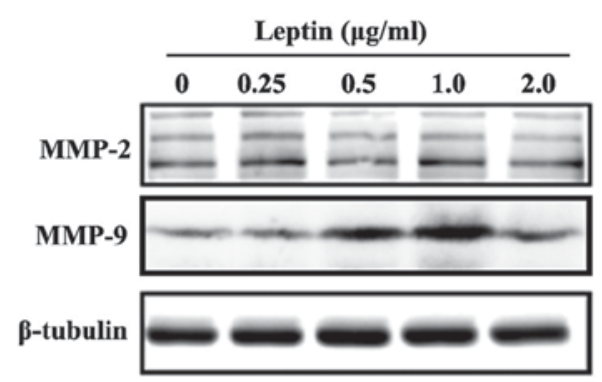

D

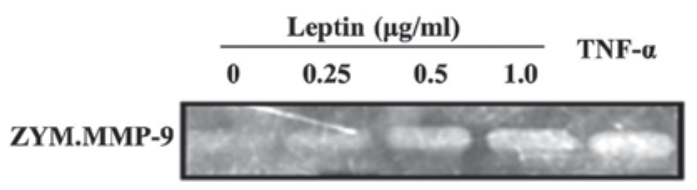

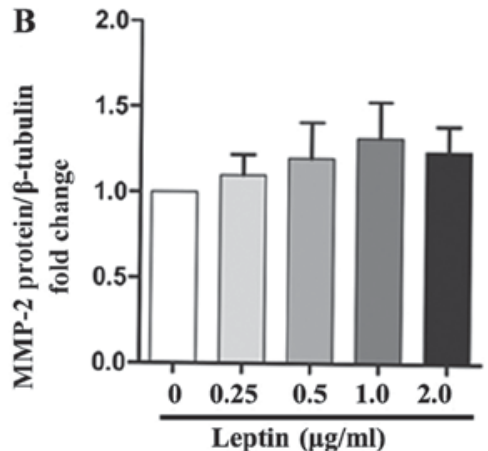
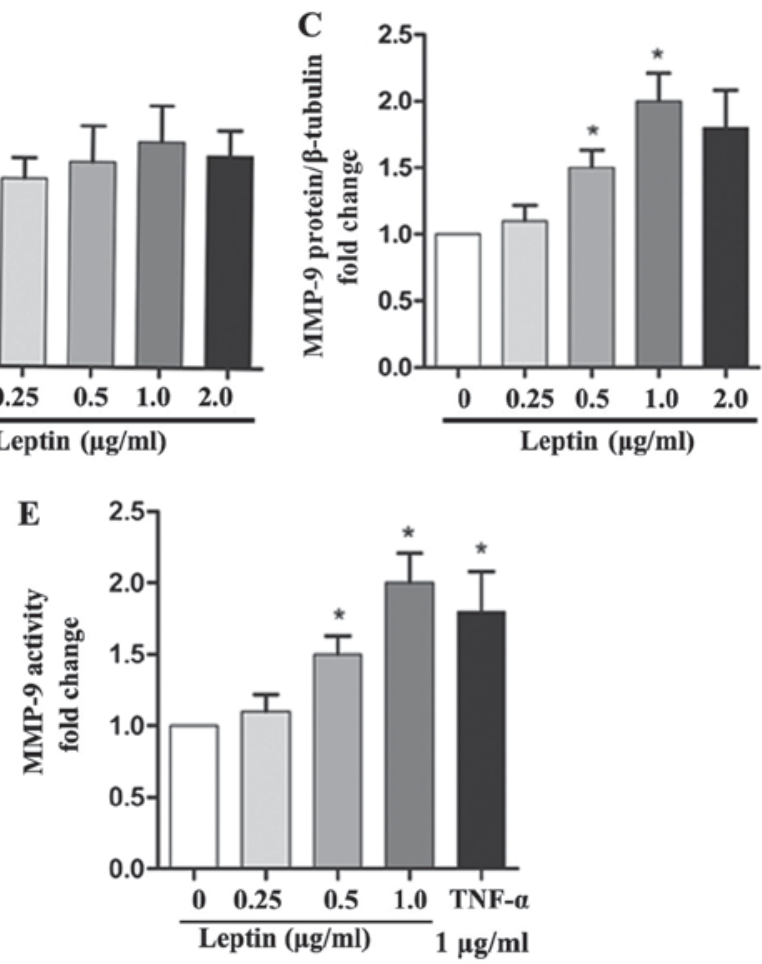

Figure 2. Leptin upregulates the expression and activity of MMP-9 in VSMCs. (A) Blots shown protein expression and histograms show quantification of (B) MMP-2 and (C) MMP-9. Leptin significantly increased the protein expression of MMP-9 but not MMP-2, in a dose-dependent manner. (D) Leptin induced the proteolytic activity of MMP-9 in VSMCs, (E) Histogram shows activity change in a dose-dependent manner. "P $<0.05$ vs. control. Data are presented as the mean \pm standard error of the mean $(n=3)$. The results are representative of three independent experiments. VSMCs, vascular smooth muscle cells; MMP, matrix metalloproteinase; TNF, tumor necrosis factor; ZYM, gel zymography.

R\&D Systems, Inc., Minneapolis, MN, USA) for $18 \mathrm{~h}$ at $4^{\circ} \mathrm{C}$. The membranes were washed and incubated for $1 \mathrm{~h}$ at room temperature with horseradish peroxidase-conjugated secondary antibody (1:5,000; BM2002; Wuhan Boster Biological Technology, Ltd., Wuhan, China). Immunoreactive bands were visualized using enhanced chemiluminescence reagent (EMD Millipore) and the optical density of bands was measured using ImageJ 1.42 (National Institutes of Health).

Statistical analysis. All in vitro experiments were performed in triplicate. One-way analysis of variance and Student's t-tests were used with SPSS software 16.0 (SPSS, Inc., Chicago, IL, USA). The statistical significance of the differences among multiple groups was tested using one-way analysis of variance and pairwise comparisons were performed using Tukey's post hoc analysis. Error bars indicate the standard error of the mean. $\mathrm{P}<0.05$ was considered to indicate a statistically significant difference.

\section{Results}

Leptin treatment significantly increases the neointima/media ratio and expression of MMP-9 in the carotid artery of ob/ob mice following carotid ligation. The mean body weight of the $o b / o b$ mice at the beginning of the study was $56.5 \pm 4.5 \mathrm{~g}$ and after 4 weeks, the mean body weights of leptin-treated mice were lower compared with the untreated animals $(50.5 \pm 5.2$ vs. $57.1 \pm 4.8 \mathrm{~g} ; \mathrm{P}<0.05)$. When the $o b / o b$ mice reached a certain weight (55-60 g), the body weight gain slowed in control group and leptin-treated group $(56.5 \pm 4.5$ vs. $57.1 \pm 4.8 \mathrm{~g}$; data not shown) (22). The body weight of the mice was also affected by invasive carotid ligation surgery. The neointima/media ratio in the carotid artery following carotid ligation of the $o b / o b$ mice was lower compared with the WT mice (1.67 vs. $10.78, \mathrm{P}<0.05)$, but was significantly higher in the $o b / o b$ mice treated with leptin (8.76 vs. $1.67, \mathrm{P}<0.05$; Fig. 1A-E). Gelatin zymography also showed that the activity of MMP-9 in the injured carotid artery was significantly higher in the leptin-treated group compared with that in the other groups $(\mathrm{P}<0.05$; Fig. 1F and $\mathrm{G})$.

Leptin upregulates the expression and activity of MMP-9 in SMCs. The present study examined the levels of MMPs in SMCs following leptin treatment.Leptin treatment significantly increased the protein levels of MMP-9 in a dose-dependent manner; however, it did not affect the protein expression of MMP-2 (Fig. 2A-C). Furthermore, using gelatin zymography, it was found that leptin treated induced MMP-9 proteolytic activity in the supernatant of SMCs in a dose-dependent manner (Fig. 2D and E). Together, these findings suggested that leptin upregulated the expression and activity of MMP-9 in SMCs.

Leptin upregulates the expression of MMP-9 by activating $A P-1$ via the MAPK/ERK/JNK signaling pathways in SMCs. It was observed that leptin treatment markedly induced cytoplasmic ERK and JNK phosphorylation in the SMCs in a time-dependent manner, and it was found that treatment of the cells with leptin in addition to pharmacological inhibitors 
$\mathbf{A}$
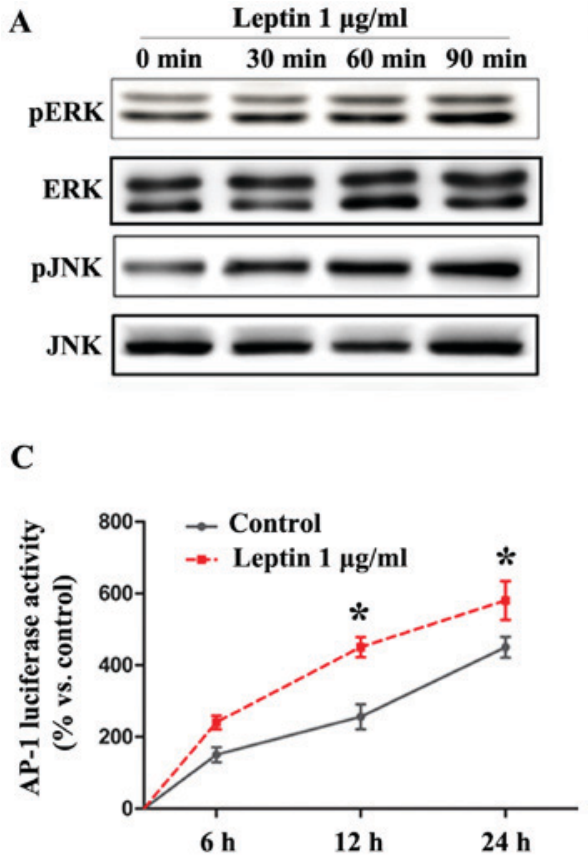

$\mathbf{B}$

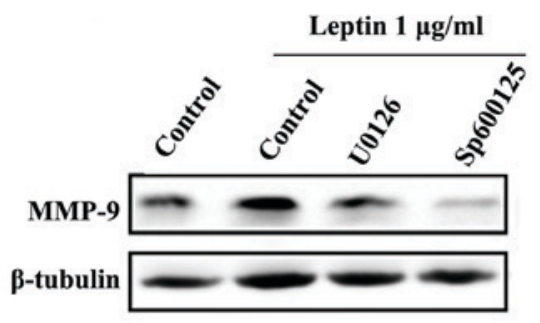

D

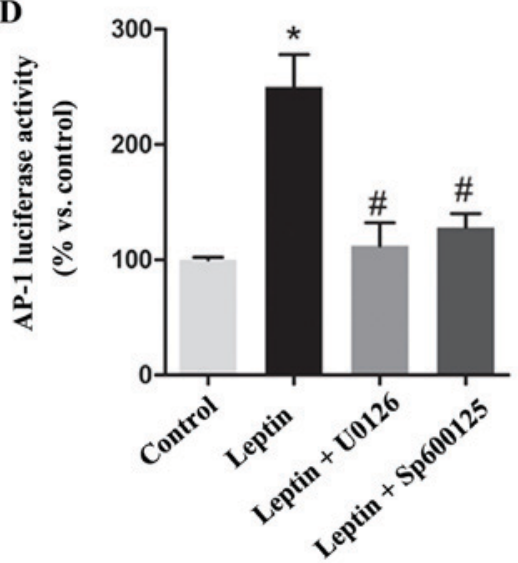

Figure 3. Western blot analysis and luciferase reporter assay of protein levels of pERK and pJNK, and transcriptional activity of AP-1 in leptin-treated VSMCs for various durations, and effects of kinase inhibitors on leptin-activated protein expression of MMP-9 and transcriptional activity of AP-1. (A) Leptin induced cytoplasm ERK and JNK phosphorylation in SMCs in time-dependent manner; the effect peaked at 90 min. (B) Pharmacological inhibitors of the MAPK/ERK pathway (U0126) and JNK (SP600125) abrogated the effects of leptin-mediated expression of MMP-9. (C) Leptin increased the transcriptional activity of AP-1 in a time-dependent manner. (D) Pharmacological inhibitors of the MAPK/ERK pathway (U0126) or JNK (SP600125) inhibited the transcriptional activity of AP-1 in the absence of leptin stimulation. ${ }^{*} \mathrm{P}<0.05$ vs. control; ${ }^{*} \mathrm{P}<0.05$ vs. leptin treatment group. Data are presented as the mean \pm standard error of the mean $(n=3)$. The results are representative of three independent experiments. MAPK, mitogen-activated protein kinase; ERK, extracellular signal-regulated kinase; JNK, c-Jun N-terminal kinase; pERK, phosphorylated ERK; pJNK, phosphorylated JNK; MMP-9, matrix metalloproteinase-9; AP-1, activator protein-1.

of the MAPK/ERK pathway (U0126) or JNK (SP600125) abrogated the leptin-mediated effects on the expression of MMP-9 (Fig. 3A and B).

AP-1 is known to be a major transcription factor that regulates the expression of MMP-9. Therefore, to understand the possible mechanisms involved in the leptin-mediated upregulation of MMP-9, the present study determined whether AP-1 was activated by leptin using a Luciferase reporter assay. Leptin significantly increased the transcriptional activity of AP-1 in a time-dependent manner, whereas pharmacological inhibitors of the MAPK/ERK pathway (U0126) or JNK (SP600125) inhibited the transcriptional activity of AP-1 by $~ 90 \%$ in the absence of leptin stimulation (Fig. 3C and D).

Leptin receptor mediated leptin-induced expression of MMP-9 in SMCs. To elucidate how leptin acts on SMCs, further experiments were performed to identify the receptor that leptin binds to on SMCs. Following systemic leptin treatment, the carotid artery of $o b / o b$ mice showed significantly increased leptin receptor expression via western blot analysis (Fig. 4A). In addition, the results of RT-qPCR analysis and agarose gel electrophoresis indicated that the leptin receptor was expressed by SMCs (Fig. 4B). Finally, the siRNA-mediated knockdown of leptin receptor abrogated the effect of leptin treatment (Fig. 4C and D).

\section{Discussion}

The secretory functions of SMCs and macrophages are crucial in intimal hyperplasia and plaque lesion instability (23). The MMP family of proteases, also known as the metzincin superfamily, are important in tissue remodeling through degrading denatured collagens, gelatins and various ECM components in different tissues. MMPs are mainly produced by macrophages and SMCs in atherosclerotic plaques (3-5). MMP-2 and -9 belong to a sub-group of gelatinases, which share similar proteolytic activity and are involved in atherosclerotic plaque rupture $(24,25)$. Soluble cytokines and cell-cell interactions have been shown to upregulate the level and bioactivity of MMPs in cells present in the normal and diseased blood vessel wall. The activation of MMP in response to inflammatory molecules, including interleukin (IL)-1, IL-4 and tumor necrosis factor- $\alpha$ (TNF- $\alpha$ ), may contribute to pathological matrix destruction and plaque rupture (6).

Leptin is an important endocrine factor, which affects cholesterol synthesis (26), but it may also act as an inflammatory factor, and plasma leptin concentrations have been found to be increased in patients with ACS, and the expression of leptin is high in vulnerable plaques (27). However, whether the expression of leptin is simply an accompanying phenomenon or a pathogenic factor in atherosclerotic plaque rupture remains to be elucidated. A previous study suggested that leptin is involved 
$\mathbf{A}$

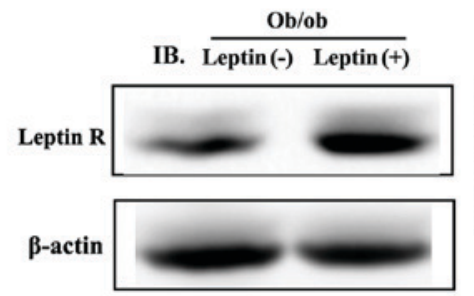

C

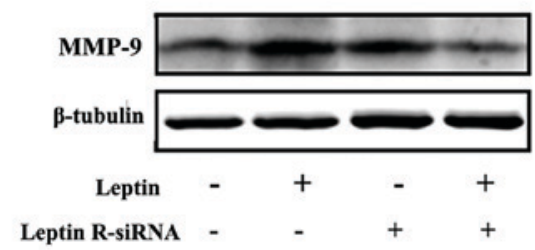

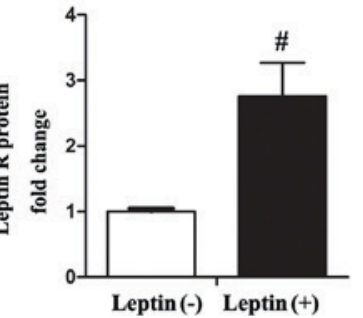

D

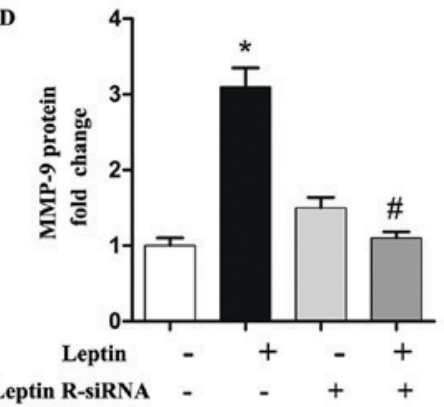

B

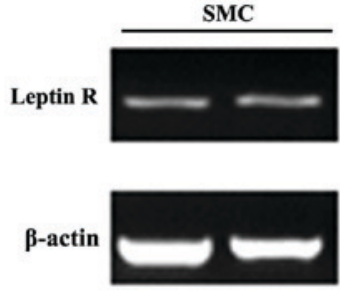

Figure 4. Leptin R mediates leptin-induced regulation of MMP-9 in the neointima and VSMCs. (A) Western blot analysis shows the protein expression of leptin R was increased in the carotid artery of $o b / o b$ mice following leptin treatment. (B) Agarose gel electrophoresis showed the leptin R gene was expressed in VSMCs. (C) Leptin R siRNA abrogated the effect of leptin-induced expression of MMP-9. (D) Representative histogram of the MMP-9 protein in different groups. " $\mathrm{P}<0.05$, vs. negative control; ${ }^{\#} \mathrm{P}<0.05$ vs. leptin treatment group. Data are presented as the mean \pm standard error of the mean ( $\mathrm{n}=3$ ). The results are representative of three independent experiments. VSMCs, vascular smooth muscle cells; leptin R, leptin receptor; MMP-9, matrix metalloproteinase-9; siRNA, small interfering RNA.

in matrix remodeling by promoting the expression of MMPs and tissue inhibitor of MMPs in vascular endothelial cells (28). In the present study, in vivo leptin treatment significantly induced the expression and activity of MMP-9 in the carotid artery following ligation in $o b / o b$ mice. In vitro, leptin upregulated the expression and activity of MMP-9, but not MMP-2, in SMCs. This indicated that leptin may have a substantial effect on plaque rupture by inducing the SMC production of MMP-9, which promotes degradation of the ECM.

Studies have demonstrated that the transcription factor AP-1 is a key transcriptional regulator responsible for the induction of MMP-9 in various types of cells (29). In the present study, it was found that leptin significantly induced the phosphorylation of ERK1/2 and JNK in SMCs. Furthermore, the results demonstrated that ERK1/2 and JNK were indispensable for AP-1-mediated expression of MMP-9 in leptin-treated SMCs. Therefore, in the present study, it was found that leptin induced the activation of AP-1 through the activity of ERK1/2 and JNK, which then facilitated AP-1 binding to promoter regions of the MMP-9 gene to promote the transcription of MMP-9.

Leptin and its receptor are expressed in SMCs $(17,18)$. Leptin receptor expression is elevated in carotid plaques relative to unstable plaques, and thus, may be involved in intimal neovascularization $(30,31)$. In the present study, leptin receptor was expressed at a high level in the mice aorta and then, following leptin treatment, a statistically significant change in the mRNA expression of aortic leptin receptor was observed in comparison with that in the control group. These results suggested that the leptin receptor served as the major receptor of leptin on SMCs and may be a novel therapeutic target for preventing leptin-induced plaque rupture.

In terms of limitations, whether the leptin receptor mediates the leptin-induced expression of MMP-9 in $d b / d b$ mice in vivo requires verification; however, similar published studies have shown that leptin is involved via combining leptin receptors in $d b / d b$ mice $(32,33)$. The present study focused on leptin stimulation of the secretion of MMP-9 in SMCs to promote plaque instability, and further examination is to be continued in future investigations.

In conclusion, the results of the present study showed that leptin significantly increased neointima hyperplasia and the expression of MMP-9 in the mouse carotid artery following carotid ligation. Leptin also significantly stimulated the expression of MMP-9, mainly by activating AP-1 via the leptin receptor/MAPK/ERK signal transduction pathways. These findings provide novel evidence that leptin may have a substantial effect on plaque rupture by promoting ECM degradation via the upregulation of MMP-9.

\section{Acknowledgements}

Not applicable.

\section{Funding}

No funding was received.

\section{Availability of data and materials}

All data generated or analyzed during this study are included in this published article.

\section{Authors' contributions}

RL performed experiments. BC was involved in data collection, analysis and interpretation, and in manuscript writing. JC performed cellular experiments and immunohistochemistry, 
and helped drafting the manuscript. JL conceived and designed the study, and analyzed and interpreted the data. All authors read and approved the final version of the manuscript.

\section{Ethics approval and consent to participate}

The experimental animal protocol was approved by the Animal Ethics Committee of Southern Medical University (permit no. SCXK2006-0116).

\section{Patient consent for publication}

Not applicable.

\section{Competing interests}

The authors declare that they have no competing interests.

\section{References}

1. Falk E, Nakano M, Bentzon JF, Finn AV and Virmani R: Update on acute coronary syndromes: The pathologists' view. Eur Heart J 34: 719-728, 2013

2. Beaudeux JL, Giral P, Bruckert E, Foglietti MJ and Chapman MJ: Matrix metalloproteinases, inflammation and atherosclerosis: Therapeutic perspectives. Clin Chem Lab Med 42: 121-131, 2004.

3. Ketelhuth DF and Bäck M: The role of matrix metalloproteinases in atherothrombosis. Curr Atheroscler Rep 13: 162-169, 2011.

4. Plutzky J: Atherosclerotic plaque rupture: Emerging insights and opportunities. Am J Cardiol 84: J15-J20, 1999.

5. Mason DP, Kenagy RD, Hasenstab D, Bowen-Pope DF, Seifert RA, Coats S, Hawkins SM and Clowes AW: Matrix metalloproteinase-9 overexpression enhances vascular smooth muscle cell migration and alters remodeling in the injured rat carotid artery. Circ Res 85: 1179-1185, 1999.

6. Newby AC: Dual role of matrix metalloproteinases (matrixins) in intimal thickening and atherosclerotic plaque rupture. Physiol Rev 85: 1-31, 2005.

7. Ha KT, Lee TK, Kwak KH, Kim JK, Kim DI, Choi DY and Kim CH: Inhibitory effect of Cho-Deung-San on human aortic smooth muscle cell migration induced by TNF-alpha through inhibition of matrix metalloproteinase-2 and -9 activity. Vasc Pharmacol 41: 83-90, 2004

8. Johnson JL, van Eys GJ, Angelini GD and George SJ: Injury induces dedifferentiation of smooth muscle cells and increased matrix-degrading metalloproteinase activity in human saphenous vein. Arterioscler Thromb Vasc Biol 21: 1146-1151, 2001.

9. Mattu HS and Randeva HS: Role of adipokines in cardiovascular disease. J Endocrinol 216: T17-T36, 2013.

10. Li R, Chen LZ, Zhao SP and Huang XS: Inflammation activation contributes to adipokine imbalance in patients with acute coronary syndrome. PloS One 11: e0151916, 2016.

11. Couillard C, Lamarche B, Mauriège P, Cantin B, Dagenais GR, Moorjani S, Lupien PJ and Després JP: Leptinemia is not a risk factor for ischemic heart disease in men. Prospective results from the Quebec Cardiovascular Study. Diabetes Care 21: 782-786, 1998

12. Piemonti L, Calori G, Mercalli A, Lattuada G, Monti P, Garancini MP, Costantino F, Ruotolo G, Luzi L and Perseghin G: Fasting plasma leptin, tumor necrosis factor-alpha receptor 2, and monocyte chemoattracting protein 1 concentration in a population of glucose-tolerant and glucose-intolerant women: Impact on cardiovascular mortality. Diabetes Care 26: 2883-2889, 2003.

13. Liu J, Butler KR, Buxbaum SG, Sung JH, Campbell BW and Taylor HA: Leptinemia and its association with stroke and coronary heart disease in the Jackson Heart Study. Clin Endocrinol (Oxf) 72: 32-37, 2010.

14. Tahergorabi Z and Khazaei M: Leptin and its cardiovascular effects: Focus on angiogenesis. Adv Biomed Res 4: 79, 2015.

15. Schneiderman J, Schaefer K, Kolodgie FD, Savion N, Kotev-Emeth S, Dardik R, Simon AJ, Halak M, Pariente C, Engelberg I, et al: Leptin locally synthesized in carotid atherosclerotic plaques could be associated with lesion instability and cerebral emboli. J Am Heart Assoc 1: e001727, 2012.
16. Tao M, Yu P, Nguyen BT, Mizrahi B, Savion N, Kolodgie FD, Virmani R, Hao S, Ozaki CK and Schneiderman J: Schneiderman, locally applied leptin induces regional aortic wall degeneration preceding aneurysm formation in apolipoprotein E-deficient mice. Arterioscler Thromb Vasc Biol 33: 311-320, 2013.

17. Schroeter MR, Eschholz N, Herzberg S, Jerchel I, Leifheit-Nestler M, Czepluch FS, Chalikias G, Konstantinides S and Schäfer K: Leptin-dependent and leptin-independent paracrine effects of perivascular adipose tissue on neointima formation. Arterioscler Thromb Vasc Biol 33: 980-987, 2013.

18. Li H, Wang YP, Zhang LN and Tian G: Perivascular adipose tissue-derived leptin promotes vascular smooth muscle cell phenotypic switching via p38 mitogen-activated protein kinase in metabolic syndrome rats. Exp Biol Med (Maywood) 239: 954-965, 2014.

19. Schäfer K, Halle M, Goeschen C, Dellas C, Pynn M, Loskutoff DJ and Konstantinides S: Leptin promotes vascular remodeling and neointimal growth in mice. Arterioscler Thromb Vasc Biol 24: 112-117, 2004.

20. Oda A, Taniguchi $\mathrm{T}$ and Yokoyama M: Leptin stimulates rat aortic smooth muscle cell proliferation and migration. Kobe J Med Sci 47: 141-150, 2001.

21. Livak KJ and Schmittgen TD: Analysis of relative gene expression data using real-time quantitative PCR and the 2(-Delta Delta C(T)) method. Methods 25: 402-408, 2001

22. Pelleymounter MA, Cullen MJ, Baker MB, Hecht R, Winters D, Boone T and Collins F: Effects of the obese gene product on body weight regulation in ob/ob mice. Science 269: 540-543, 1995.

23. Ross R: Rous-Whipple award lecture. Atherosclerosis: A defense mechanism gone awry. Am J Pathol 143: 987-1002, 1993.

24. Galis ZS, Sukhova GK, Lark MW and Libby P: Increased expression of matrix metalloproteinases and matrix degrading activity in vulnerable regions of human atherosclerotic plaques. J Clin Invest 94: 2493-2503, 1994.

25. Kampoli AM, Tousoulis D, Papageorgiou N, Antoniades C, Androulakis E, Tsiamis E, Latsios G and Stefanadis C: Matrix metalloproteinases in acute coronary syndromes: Current perspectives. Curr Top Med Chem 12: 1192-1205, 2012.

26. Kosztáczky B, Fóris G, Paragh G Jr, Seres I, Zsiros E, Koncsos P, Balogh Z and Paragh G: Leptin stimulates endogenous cholesterol synthesis in human monocytes: New role of an old player in atherosclerotic plaque formation. Leptin-induced increase in cholesterol synthesis. Int J Biochem Cell Biol 39: 1637-1645, 2007.

27. Lee K, Santibanez-Koref M, Polvikoski T, Birchall D, Mendelow AD and Keavney B: Increased expression of fatty acid binding protein 4 and leptin in resident macrophages characterises atherosclerotic plaque rupture. Atherosclerosis 226: 74-81, 2013.

28. Park HY, Kwon HM, Lim HJ, Hong BK, Lee JY, Park BE, Jang Y, Cho SY and Kim HS: Potential role of leptin in angiogenesis: Leptin induces endothelial cell proliferation and expression of matrix metalloproteinases in vivo and in vitro. Exp Mol Med 33: 95-102, 2001

29. Moon SK, Kim HM and Kim CH: PTEN induces G1 cell cycle arrest and inhibits MMP-9 expression via the regulation of NF-kappaB and AP-1 in vascular smooth muscle cells. Arch Biochem Biophys 421: 267-276, 2004.

30. Schneiderman J, Simon AJ, Schroeter MR, Flugelman MY, Konstantinides S and Schaefer K: Leptin receptor is elevated in carotid plaques from neurologically symptomatic patients and positively correlated with augmented macrophage density. J Vasc Surg 48: 1146-1155, 2008

31. Kang SM, Kwon HM, Hong BK, Kim D, Kim IJ, Choi EY, Jang Y, Kim HS, Kim MS and Kwon HC: Expression of leptin receptor $(\mathrm{Ob}-\mathrm{R})$ in human atherosclerotic lesions: Potential role in intimal neovascularization. Yonsei Med J 41: 68-75, 2000.

32. Taleb S, Herbin O, Ait-Oufella H, Taleb S, Herbin O, Ait-Oufella H, Verreth W, Gourdy P, Barateau V, Merval R, et al: Defective leptin/leptin receptor signaling improves regulatory $\mathrm{T}$ cell immune response and protects mice from atherosclerosis. Arterioscler Thromb Vasc Biol 27: 2691-2698, 2007.

33. Luo W, Bodary PF, Shen Y, Wickenheiser KJ, Ohman MK, Guo C, Bahrou KL, Myers MG Jr and Eitzman DT: Leptin receptor-induced STAT3-independent signaling pathways are protective against atherosclerosis in a murine model of obesity and hyperlipidemia. Atherosclerosis 214: 81-85, 2011. 